\title{
Retóricas ambivalentes: \\ ressentimentos e negociações em contextos de sociabilidade juvenil na Cidade do Cabo (África do Sul)*
}

\section{Resumo}

Laura Moutinho**

Pedro Lopes ${ }^{* * *}$

Marcio Zamboni

Mario Ribas***

Elaine Salo ${ }^{* * * * * *}$

O objetivo deste artigo é refletir sobre um conjunto de questões relativas ao racismo, à sexualidade e ao contato intercultural na África do Sul, mais especificamente em Cape Town. Esta cidade, que já foi reconhecida como democrática, com expressiva população coloured e gay friendly se apresenta atualmente como uma das mais desiguais da África do Sul pós- apartheid. Percorremos trajetórias de homens $e$ mulheres homo $e$ heterossexuais, de diferentes raças e regiões, no sentido de abrir a escuta para suas experiências, dar inteligibilidade a seus campos de negociação e qualificar formas ressemantizadas de exclusão. Objetiva-se analisar uma nova e relativamente recente sensibilidade social advinda com a "rainbow nation" - a experiência de mistura em sua articulação com marcadores sociais da diferença.

Palauras-chave: Raça, Sexualidade, Gênero, Reconciliação, Negociação/Exclusão, África do Sul, Cidade do Cabo.

\footnotetext{
* Recebido para publicação em setembro de 2010, aceito em outubro de 2010.

** Professora do Departamento de Antropologia da Universidade de São Paulo. lmoutinho@usp.br;

****Pesquisadores do Núcleo de Estudos dos Marcadores Sociais da Diferença (NUMAS/USP).pedro.lopes@usp.br; marciobz@gmail.com

**** Doutorando University Cape Town.mfribas@yahoo.co.uk

***** Diretora do Institute for Women's and Gender Studies e professora da Universidade de Pretória. elaine.salo@up.ac.za
}

cadernos pagu (35), julho-dezembro de 2010:139-176. 
Retóricas ambivalentes

Ambivalent Rhetorics: Resentment and Negotiation

in Youth Sociability Contexts in Cape Town (South Africa)

\begin{abstract}
The goal of this article is to reflect upon a series of questions concerning racism, sexuality and intercultural contact in South Africa and, specifically, Cape Town. The city, once acclaimed as democratic, with an expressive colored and gay-friendly population, has recently been (re)presented as one of the most unequal cities of post-apartheid South Africa. Here, we follow the life trajectories of some men and women, both homo- and heterosexual, of different races and regions, listening to their experiences in order to reveal their fields of negotiation and to thus qualify some re-signified forms of exclusion. Specifically, our objective is to analyze a new and relatively recent social sensibility arising within the "rainbow nation" (the experience of admixture in intersectionality with distinct social difference markers) that does not necessarily imply sexual-affective inter-racial dating.
\end{abstract}

Key Words: Race; Sexuality; Gender; Reconciliation/Exclusion; South Africa; Cape Town. 
Laura Moutinho et alii

\section{A cidade e seus personagens}

No contexto do pós-apartheid a Cidade do Cabo vem ganhando destaque por sua singularidade frente às novas dinâmicas de exclusão e poder. Reconhecida na "old South Africa" como uma cidade mais democrática, mestiça e onde as leis segregacionistas, para muitos, eram mais brandas, atualmente se destaca como "a mais desigual" da África do Sul, tanto nas falas de seus moradores quanto na mídia.

Essa percepção local precisa ser observada em sua complexidade, visto que compreende uma relação espaçotemporal específica, articulada às novas hierarquias de poder que vêm ganhando espaço no país a partir da transformação concomitantemente legal, moral e ontológica (Moutinho, 2009) que foi (e vem sendo) construída após o fim do regime racial. A formulação de desigualdade e o lugar que a cidade ocupa no novo cenário nacional contrastam de modo não gratuito com outra forma de entendimento veiculada socialmente: a África do Sul detém a "mais progressista Constituição do mundo", sendo referência (de fato, um caso paradigmático) nos processos de reconstituição do tecido social pós-regimes autoritários com a Truth and Reconciliation Commission. Como parte do compromisso de "romper com o passado" e "lutar e resistir a todas as formas de discriminação", em 2006 foram legalizadas as uniões entre pessoas do mesmo sexo pelo casamento ou pela união civil. Essa disposição legal - em conjunto com outras, como as políticas de ação afirmativa especialmente representadas pela

1 No preâmbulo da Constituição lê-se: "Nós, povo da África do Sul, reconhecemos as injustiças de nosso passado; (...) Acreditamos que a África do Sul pertence a todos os que nela vivem, unidos em nossa diversidade. Nós, portanto, por meio de nossos representantes livremente eleitos, adotamos esta Constituição como a lei suprema da República de modo a - Sanar as divisóes do passado e estabelecer uma sociedade baseada em valores democráticos, justiça social e direitos humanos fundamentais (...)" (Tradução e ênfases nossas. África do Sul, 1996). 
Retóricas ambivalentes

Employment Equity Act, de 1998 e a Black Economic Empowerment Act (BEE), de 2003 - informa o reposicionamento do país no cenário internacional que, a princípio, procura atender as demandas por justiça social, operando tanto em termos de reconhecimento quanto de redistribuição ${ }^{2}$ - tendências que tiveram diferentes ênfases nos governos de Nelson Mandela e Thabo Mbeki. Como afirmou uma entrevistada ao ser perguntada sobre o pós-apartheid:

A maior mudança que tenho visto é que as pessoas se misturam mais e há mais relacionamentos inter-raciais. Eu lembro das primeiras vezes que vi um casal inter-racial: as pessoas ao redor sempre reagiam, nem sempre de maneira positiva - e ficavam encarando. Mas agora há as escolas mistas e você vê que os grupos de amizade também estão mais misturados. Além disso, casais gays estão se tornando mais públicos, e você vê mais homens e mulheres gays de mãos dadas, ou manifestando afeto abertamente. Também há mais casais do mesmo sexo com crianças andando pelos shoppings... (Anne ${ }^{3}$, coloured, 24 anos e heterossexual)

Nosso objetivo neste artigo é seguir as percepções $e$ experiências particulares dos entrevistados (como a anteriormente citada, que nos fornece um primeiro quadro de compreensão dessas transformações) com o intuito de dar inteligibilidade ao processo de difusão social desses fenômenos. Seguiremos as narrativas de indivíduos que se posicionam de modo não unívoco no interior de redes circulatórias, relacionais, desiguais $e$ contíguas. Esses novos regimes de verdade autorizam sujeitos $e$ identidades, mas são igualmente permeados por recusas e novos modos de subjetivação que operam concomitantemente com

\footnotetext{
2 Ver sobre o tema Fraser (2007).

3 Os nomes dos entrevistados foram alterados, de modo a preservar suas identidades.
} 
formas atualmente desautorizadas, porém presentes de modo tenso no cotidiano.

Não se pretende neste artigo, entretanto, "repertoriar" as leis e normas hegemônicas, aferindo "a realidade contra esse parâmetro" (Fonseca, 2005), tampouco ignorar as complexas controvérsias que acompanharam (e ainda se fazem presentes) a implementação dessa malha de regulações e reparações (ou mesmo os dispositivos de acesso à justiça) que vem administrando, e igualmente produzindo, novos conflitos, hierarquias $e$ formas de poder. A fala de uma das entrevistadas (Veronica, White, Lésbica, de 24 anos) fornece uma pista a respeito da intricada interação entre a violência cotidiana, à qual (ainda que de modos distintos) todos estão expostos, o reconhecimento jurídico e a legitimidade social de sujeitos, comportamentos e posições. Na sua percepção:

[Os direitos LGBT na África do Sul] São destacados como um dos conjuntos de leis dos mais sofisticadamente elaborados do mundo, mas eu não acredito que a política necessariamente se traduza em prática. Por exemplo, homens que são estuprados... Eu tenho um amigo na minha aula de sociologia que conhece homens que foram estuprados e depois ridicularizados pela polícia.

- Estuprados por homens?

- Sim, gays estuprados por homens.

Assombradas pelos altos índices de estupro e violência (com forte marca racial e de gênero), a África do Sul e a Cidade do Cabo se vêem atualmente frente a inúmeros desafios relativos aos rearranjos sociais e políticos recentes. Desse modo, interessa-nos inquirir essa sensibilidade histórica e social que, ao mesmo tempo, atua em campos morais de disputa, produzindo eventualmente formas de empatia e solidariedade com pessoas expostas $e$ vulneráveis à exclusão e, igualmente, homogeneíza percepções 
Retóricas ambivalentes

através de discursos dicotômicos, literalistas (Crapanzano, 2001) e frequentemente redutores de experiências densas.

O território desta análise é o tecido social dessa cidade, símbolo de uma nova compreensão da desigualdade social que, entretanto, se mantém, em outro nível, festejada. Para muitos, a Cidade do Cabo é uma alternativa viável no sentido de se experienciar as consequências sociais desse complexo (e recente) reconhecimento jurídico de novos sujeitos sociais, especialmente no que tange à homossexualidade nas camadas médias/altas embora não seja assim compreendida para os blacks e/ou homossexuais em situação de pobreza.Nossa análise será conduzida pelas experiências de vida de alguns jovens moradores desse contexto urbano. No trabalho realizado, notamos que esses jovens (e seus familiares), a princípio, não passaram diretamente por uma experiência traumática de luta contra o regime. Nenhum deles tampouco apresentou narrativas heróicas de resistência ao apartheid. Alguns partilharam experiências de situações cotidianas vividas no fim do regime. Outros nasceram quando o apartheid já estava sendo desmantelado e muitos sequer possuem memória das restrições que as leis raciais impuseram, tendo crescido numa época de mais esperança e liberdade, quando novas fronteiras sociais estavam sendo forjadas. Todas essas narrativas $e$ percepções lançam luzes sobre as contenções e negociações cotidianas encenadas na "nova" África do Sul. 
Laura Moutinho et alii

\section{Geografias da cidade ${ }^{4}$}

O objetivo deste item é apresentar ao leitor as geografias urbanas que foram percorridas, mapeadas e analisadas pelos pesquisadores que compuseram a equipe local. ${ }^{5}$

A Cidade do Cabo possui uma geografia exuberante e complexa. De certa maneira, trata-se de uma beleza com um toque trágico, visto que a belíssima combinação entre mar $e$ montanha numa cidade pouco verticalizada evidencia a força da lógica urbana racial organizada no período do apartheid. Atualmente, a Cidade do Cabo pode ser um verdadeiro paraíso, mas, de fato e sobretudo, somente para os que são capazes de sustentar o alto padrão de vida que a cidade exige.

Podemos começar com um contraste, expresso por Tiisetso (black, lésbica, de 23 anos), entre duas eras - com foco na experiência urbana e na lógica racista:

O racismo aqui na Cidade do Cabo é pior... Eu lembro de quando, na década de 1990, eu e meu primo fomos a um bar no centro para beber alguma coisa. Só tinha whites. Eu

\footnotetext{
4 Em cada uma das seis cidades que compuseram a pesquisa internacional, foram conduzidas etnografias em espaços de sociabilidade, entrevistas em profundidade com pessoas selecionadas a partir das experiências etnográficas, $e$ aplicação de questionários fechados, que funcionaram como fonte suplementar de informação. No caso da Cidade do Cabo, o resultado foi a produção de 40 relatos etnográficos, 31 entrevistas - 6 a mais do que o previsto, visando dar conta especialmente das experiências e trajetórias dos sujeitos moradores de townships-e 48 questionários aplicados.

5 A coordenação local desta pesquisa foi realizada por Elaine Salo. Mario Ribas foi coordenador de campo do trabalho. Fizeram parte da equipe de pesquisadores: Blessing Masiyakurima, Cleo de Vos, Dale Choudree, Deborah Diedericks, Julie Aaboe, Martha Qumba e Phyllida Cok. Pedro Lopes e Marcio Zamboni sistematizaram os dados etnográficos e as entrevistas em profundidade produzidas pela equipe de Cape Town sob a orientação de Laura Moutinho, que atuou na coordenação geral da pesquisa e trabalhou em parceria com a equipe local. As traduções do material de campo são de Pedro Lopes, sob supervisão da professora Laura Moutinho.
} 
Retóricas ambivalentes

acho que era um dos bares só para whites: não havia nada escrito, mas eu podia ver e sentir isso. Dava para ver que não era para blacks, sabe? As coisas mudaram agora, nós todos podemos ir ao mesmo shopping... Eu acho que as coisas mudaram, mesmo para eles: agora tem whites até em hospitais públicos e abrigos. É diferente de antes, quando os whites tinham seus próprios lugares e a palavra final no governo.

Tiisetso nos fornece pistas sobre a forma como as divisões raciais operavam no espaço urbano no período do apartheid. Um aspecto que não deve passar despercebido de sua fala refere-se à sensação de uma adequação racial específica que emanava do ambiente ainda que não houvesse explicitamente uma indicação de que o bar fosse, de fato, exclusivo para whites. Sua compreensão dessa lógica nos remete ao sistema de classificação racial sul-africano anterior à democracia (mas que mantém ecos em níveis diferenciados atualmente), quando além da "convivência", um dos critérios de registro racial era "aceitação" pelo grupo, que agregado à "aparência", "origem/descendência" construía uma forma estática e o mais precisa possível de categorização e controle. ${ }^{6}$

O debate sobre a rigidez classificatória com base na raça é clássico na África do Sul. Existe um consenso na literatura acerca do ponto muito bem sumarizado por Crapanzano - cujas palavras, aliás, ecoam as proferidas por Mary Douglas (1967) em Pureza e Perigo, vinte anos antes. Na percepção do autor,

(...) um objeto ou ser (...) classificado torna-se para sempre aquele objeto ou ser. Ele tem uma identidade, participa de

6 As quatro principais leis que organizaram a montagem do regime foram: a Mixed Marriage Act (de 1949, que criminalizava os casamentos inter-raciais), a Immorality Act (de 1950, lei que proibia o intercurso carnal inter-racial), a Group Areas Act e Registration Population Act (ambas também de 1950, que determinavam, respectivamente, as moradias separadas com base na raça apoiando-se na forma oficial como as pessoas eram classificadas racialmente). 
uma essência específica. Está sujeito a determinadas regularidades, que são entendidas como regras ou leis da natureza, e tem seu lugar próprio dentro de uma conjuntura específica do universo, de certa forma à maneira de uma peça num quebra-cabeças. A classificação essencialista é estática. Qualquer mudança de identidade, de essência, de regularidade ou de lugar, coloca um problema; em realidade, qualquer mudança ameaça o próprio sistema classificatório (Crapanzano, 1985:20). ${ }^{7}$

As duas das principais leis de fundamental importância no período do apartheid evidenciam que a criminalização do sexo e dos casamentos inter-raciais são pontos-chave para a manutenção da pureza racial e concomitantemente efeito e construtor da "rigidez classificatória". De fato, a gestão da sexualidade a partir de critérios raciais na África do Sul foi central na manutenção do sistema, dos privilégios e da superioridade white masculina (cf. Moutinho, 2004a e b).

Nesse sentido, um rigoroso planejamento foi desenvolvido para impossibilitar qualquer processo de empatia com um outro distinto, bem como qualquer forma de solidariedade ou de identificação. Evitou-se aquilo que Fernando Rosa Ribeiro (1995) chamou de a criação de um "blunting process" (processo de embotamento) proporcionado pelo contato e pela miscigenação.

Ao comparar dois momentos históricos, Tiisetso não aborda as limitações raciais de acesso ao espaço urbano apenas sob a ótica dos excluídos. Um aspecto interessante de sua percepção refere-se à limitação que atinge a todos - ainda que de modo diferenciado pelo maior benefício às estruturas de poder. Diferentemente do Brasil, onde frequentemente os "brancos" aparecem de modo opaco nas análises sobre a questão racial, na África do Sul, a pregnância dessa clivagem marca racialmente a percepção que grupos $e$ indivíduos têm de si, especialmente no que tange a não eliminação desse marcador da diferença $e$ da

7 Tradução de Fernando Rosa Ribeiro. 
Retóricas ambivalentes

desigualdade nas interações cotidianas. Em sua fala, pode-se ainda notar como os whites, que atualmente também podem frequentar todos os espaços, experimentam certos custos sociais em consequência da perda de poder e do privilégio raciais.

Mais uma vez, Tiisetso expressa ideias e sentimentos comuns a muitos na África do Sul e em Cape Town:

A África do Sul ainda é racista, e a Cidade do Cabo é pior, por causa do apartheid. A forma como fomos criados era racista, porque alguns de nós nascemos no período do apartheid. Tipo uma árvore: uma árvore tem raízes. Mesmo que você arranque a árvore, algumas raízes vão continuar presas ao chão, entende? Apesar de haver algumas iniciativas para se livrar do racismo, ele persiste aqui, porque nós crescemos com ele. A gente meio que herdou dos nossos ancestrais, então é difícil que simplesmente desapareça ou vá embora... não é fácil, sabe...

A metáfora da árvore (e suas profundas ramificações) é utilizada por muitos sul-africanos para explicar o legado racista (e podemos acrescentar o próprio protocolo de identificação racial dos indivíduos no cotidiano) que, na sua complexidade, não pode simplesmente ser removido, mesmo com as iniciativas de cunho concomitantemente moral, legal e social em curso no país. A "herança dos ancestrais" - para nos atermos à forma como Tiisetso formulou sua percepção - se refere ao apartheid, mas não exatamente ao seu formato legal. Não se trata apenas de inquirir a força das identidades raciais cristalizadas naquele período, mas, sobretudo, evidenciar como a raça se construiu de modo estático justamente por articular um sentido de comunidade, conformando tradições, línguas, experiência e culturas específicas.

No desenho urbano da cidade, esse esforço representou uma configuração espacial estrategicamente esquadrinhada. A distribuição dos espaços na Cidade do Cabo é certamente herdeira da lógica segregacionista, em tensão com os esforços nacionais por "reconciliação" e as recentes reconfigurações 
políticas no pós-1994. Afirma-se com isso a importância da distribuição física dos serviços urbanos na definição de acessos, interdições e circulações, aspectos significativos tanto para o planejamento e a experiência nas cidades, quanto para sua representação e compreensão analítica. Como defendem Ferguson e Gupta (2000:47)

a localização física e o território físico, durante tanto tempo a única grade sobre a qual a diferença cultural podia ser desenhada, precisa ser substituída por grades múltiplas que nos permitam ver que conexões e contiguidade - de modo mais geral, a representação do território - variam consideravelmente graças a fatores como classe, gênero, raça e sexualidade, e estão disponíveis de forma diferenciada aos que se encontram em locais diferentes do campo do poder.

Nesse sentido, a etnografia dos bares e boates na Cidade do Cabo busca articular linhas espaciais a sistemas de classificação social da diferença, entrecruzando especialmente categorias de raça, classe e orientação sexual.

A apresentação do mapeamento dos lugares de sociabilidade etnografados pelos pesquisadores na Cidade do Cabo, a seguir, está divida em três bairros ou regiões, agrupados pela proximidade espacial dos estabelecimentos visitados nessas localidades. Essa divisão buscou representar um olhar distante sobre a distribuição dos frequentadores, segundo as categorias de diferenciação que orientam esta análise - um corte instrumental que permite estabelecer pontes e identificar circuitos.

A opção por respeitar a proximidade espacial dos locais nos bairros, na descrição da cena noturna da cidade, permite que visualizemos os públicos que os atravessam. Ou seja, a divisão não se sustenta se pensada em termos de simples distribuição de maiorias raciais, de classe ou orientação sexual, o que poderia organizar locais mais frequentados por blacks ou whites, lésbicas, gays ou heterossexuais, e sim por um corte que possibilita que 
Retóricas ambivalentes

esses marcadores sociais da diferença apareçam de diferentes formas nos três espaços. Essa organização metodológica possibilitou enfatizar a negociação realizada pelos frequentadores, bem como algumas das formas de circulação possíveis presentes nas três regiões:

- City Centre (centro da cidade)

- Observatory

- Green Point e De Waterkant.

\section{Mapa 1}

As regiões de City Centre, Observatory, Green Point e De Waterkant ${ }^{8}$

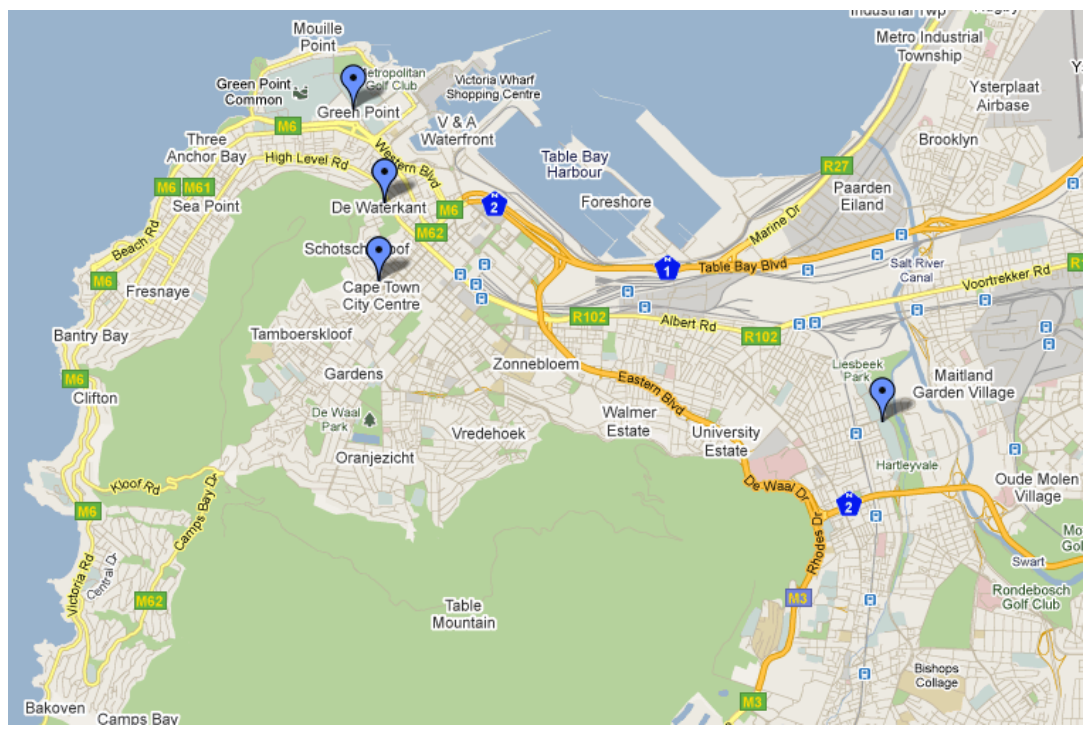

Os bairros citados estão assinalados pelos balões. ${ }^{9}$

\footnotetext{
8 Mapa criado a partir de http://maps.google.com.br/ [acesso: julho de 2010].

9 Embora existam circuitos de sociabilidade significativos cruzando diferentes subúrbios aqui não representados, ou diferentes cenas em townships, privilegiamos os espaços citados nas entrevistas.
} 
Em City Centre, a Long Street destaca-se como um circuito noturno de bares, restaurantes e boates bastante reconhecido pelos moradores da Cidade do Cabo. O público que frequenta a região compõe-se, inclusive, de turistas internacionais, dada a concentração de hotéis ao longo da colorida avenida. Veronica, já citada anteriormente, moradora de uma região residencial de luxo, fala de sua percepção do local:

- É bem tranquilo, bastante cosmopolita... Quero dizer, é um lugar onde ser gay é uma coisa normal... Eu também gosto muito do fato de ser uma área bem misturada, onde você vê turistas, pessoas vindas de outros lugares.

- Misturada em termos de nacionalidade?

- Sim.

Nas visitas à região da Long Street, os pesquisadores relatam a presença de um público jovem multi-racial, principalmente estudantes e jovens profissionais, que frequentam boates, restaurantes, pubs, cafés e fast-foods. Embora os encontros erótico-afetivos entre pessoas do mesmo sexo não estivessem visíveis no momento em que as etnografias foram realizadas, é notável uma certa "abertura" à diversidade de comportamentos sexuais, evidenciada pela presença de casais inter-raciais.

Ao desenhar um quadro geral da região e arredores, os pesquisadores apontaram a presença de prostituição nas ruas $e$ venda de drogas. Um dos pesquisadores relacionou a venda de drogas à presença de um público jovem, basicamente estudante, que tanto frequentaria quanto moraria na região. Contudo, em nenhum relato, ou mesmo nas observações dos entrevistados, a violência pareceu ser um tema candente.

A badalada Long Street une-se em linha reta a outras ruas: a nordeste, chegando à orla marítima, e a sudoeste, adentrando na região residencial do Gardens. Nas etnografias, o bairro é descrito como notadamente "trendy" (da moda), ocupado por 
jovens profissionais e estudantes - categorias recorrentes para definir o público dos estabelecimentos em City Centre.

Há um distinguível corte de classe que parece limitar os acessos à região da Long Street. Alguns entrevistados associam esse corte a uma clivagem de raça. Nas etnografias, há uma sensível maioria white nas descrições dos estabelecimentos da região central. Contudo, os pesquisadores notaram cenas interraciais em alguns dos locais visitados: além disso, os sites de alguns desses bares expõem uma programação musical especialmente voltada a uma cultura "township pop". Certamente, há que se pesar aí, conforme apontaram alguns dos pesquisadores e entrevistados, a recente ascensão social experienciada especialmente por jovens blacks contemplados nas políticas de ação afirmativa instaladas na África do Sul a partir de fins da década de 1990.

No quadro dos locais etnografados, é possível aproximar a vida noturna da região central, dos arredores da Long Street, à cena de Observatory, alguns quilômetros a leste do centro. $\mathrm{O}$ bairro fica próximo à UCT (University of Cape Town) e das residências estudantis, atraindo um público notadamente jovem.

Os pesquisadores apontaram uma clientela diversa do ponto de vista da orientação sexual: eventuais casais de pessoas do mesmo sexo e parcerias inter-raciais. Assim, foi descrita uma cena frequentada por pessoas de diferentes raças, fazendo-se a ressalva de um corte significativo de classe.

A programação cultural dos estabelecimentos da região parece apresentar pistas significativas à definição de seu público majoritário. Bsy, black, heterossexual, de 22 anos, estudante da UCT e frequentadora esporádica da região, diz ir aos bares do Observatory para assistir a shows de bandas e ouvir a certos tipos musicais. Tonkiso, black, gay, de 24 anos, escolhe alguns bares do bairro, especialmente, por sua atmosfera próxima a dos townships, e preços de itens de consumo mais acessíveis do que aqueles do circuito da Long Street. De fato, foram observados bares e boates 
frequentados por um público oriundo de classes mais baixas em relação ao quadro geral do circuito central.

Conforme uma das etnografias, há estabelecimentos na região que oferecem, além da programação noturna habitual a bares e boates, palestras, exibição de filmes e documentários que não estão presentes no circuito comercial e debates sobre temas de interesse: dentre os quais se destacam raça, sexualidade, violência e problemas de identidades sociais.

Mandla, rapaz black, 21 anos, heterossexual, que viveu na Suíça e nasceu em Zimbábue, observa:

- Para que região você costuma ir quando sai com amigos? Agora estamos em Observatory, que é bem multi-cultural... Você gosta de áreas como esta ou prefere ir a lugares diferentes?

- Bem, isso varia. Tem lugares aqui bem mais acessíveis, mais relaxados... Você não precisa bancar uma imagem, como em outras regiões. Eu gosto daqui, de Observatory. Gosto também das áreas estudantis de Rondebosch, porque acabo encontrando gente com uma experiência de vida muito parecida com a minha. Eventualmente eu vou ao centro da cidade, às boates, onde encontro gente com diferentes estilos de vida.

Embora a faixa-etária do público na região do bairro de Observatory apresente uma variação maior do que a da Long Street, descrita como mais jovem, a região foi associada a certa imagem de juventude, construída ao redor de um ethos universitário e artístico, delineando uma cena aparentemente mais diversa do ponto de vista racial, e menos "trendy" (da moda), do ponto de vista de estilo. Se é possível aproximar a cena noturna das duas regiões em função de um público observado como jovem, há ênfases diferenciadas nas representações gerais desses dois espaços.

Vale notar que diversos entrevistados, de diferentes grupos de cor/raça/etnia, classes sociais e orientações sexuais, observaram 
Retóricas ambivalentes

que frequentam espaços tanto na região central quanto em Observatory. Os entrevistados com maior circulação pela noite da cidade, além de frequentar esse circuito apontado como jovem, por vezes manifestaram também sua presença nos bairros do Green Point e De Waterkant. A região é reconhecida como "Pink Strip" ou "Gay Village" da Cidade do Cabo, circuito de bares, restaurantes e boates cujo público é tipicamente categorizado como homossexual (com significativo poder de consumo), embora se note também a presença, ainda que circunscrita, de pessoas que se apresentam como heterossexuais.

Alguns espaços dessa região apresentam um público majoritariamente masculino, white, homossexual e de classes mais altas. A própria localização geográfica dos bairros parece contribuir para essa configuração: a oeste do centro, é preciso atravessá-lo para chegar à "Pink Strip", vindo-se dos bairros e townships mais ao leste. Contudo, há bares e clubes que apresentam públicos mais misturados do ponto de vista racial, o que levou os pesquisadores a relativizarem certos critérios de definição de classe. Nesse sentido, o alto preço de itens de consumo nos bares parece, em alguns casos, ser contrabalanceado com a não cobrança de taxa na entrada. A circulação de alguns entrevistados aponta para a pertinência dessa observação: Tonkiso, morador de um township que experimenta certa ascensão social, relata uma circulação ampla pela cena noturna da Cidade do Cabo. Isso não significa que sua circulação não seja permeada por tensões:

- Quais são os lugares que você frequenta?

- Ah, eu vou bastante a Observatory...

- Quais lugares de Observatory?

- Costumo ir ao A Touch of Madness... Quando estou afim de um clima mais próximo dos townships vou ao The Edge, sabe, tem mais uma cara de shebeen, mas é na região central... E é muito bacana...

- Onde fica esse The Edge? 
- Em Observatory, na Lower Main Road... E eu obviamente adoro a Long Street, além do Green Point, onde ficam todos os bares gays...

- E como você se sente nesses lugares que você frequenta, você se sente que precisa ficar alerta?

- Isso é curioso. No Green Point é claro você pode deixar rolar completamente, mas por causa do contexto, porque é um lugar gay. Em alguns lugares de Observatory que eu vou com amigos eu posso baixar a guarda. Mas obviamente tem gente nesses espaços fazendo julgamentos e partindo de premissas sobre você baseadas na sua raça ou coisa do tipo. Você passa por essa experiência quando sai à noite para os clubes e boates, quando vai a essas boates gays. Claro, elas estão no Green Point ou outros bairros no centro da cidade. E dá pra saber dá pra dizer quem é bem-vindo e quem não é, você consegue sentir quem pode e quem não pode ficar com quem...

Nesse cenário, vale mencionar o Café Manhattan ${ }^{10}$, primeiro café voltado especificamente ao público homossexual no país. Tanto entre os frequentadores quanto entre os funcionários, há uma ampla maioria masculina, como aponta Paul, white, heterossexual, de 22 anos, um funcionário do local na época da entrevista:

- Em Cape Town você sai basicamente com pessoas que conheceu no trabalho e que, portanto, são quase todas gays?

- Bom, 90\% da clientela do Café Manhattan é gay, essa é uma área muito gay. Por isso mesmo é chamada de "Pink Strip" [faixa cor-de-rosa]... A maioria é masculina, eu diria que nem $10 \%$ são mulheres.

- Então você geralmente sai com homens gays e vai a casas noturnas gays. Você pode me falar como eles são em termos de idade, classe, raça...

- As idades variam um pouco, de 22 a 32 anos, a classe é

${ }^{10} \mathrm{http}: / / w w w . m a n h a t t a n \cdot c o . z a /$ 
Retóricas ambivalentes

mais ou menos a mesma, já que a maior parte trabalha junto. Alguns dos clientes são tipo arquitetos ou estilistas, eu diria que de uma classe bastante privilegiada.

- E você sai com o pessoal que trabalha na cozinha?

- Não, eles de fato não saem com a gente.

- E eles são predominantemente homens blacks e heterossexuais?

- Sim, mas na verdade nem tem tantos gays assim trabalhando aqui. O dono, um gerente, e acho que três garçons são gays.

- Isso é bastante surpreendente! Mas você diz que 90\% da sua clientela é composta de homens gays, como isso afeta você? Digo, deve haver algum tipo de paquera...

- Ah, claro.

- Mas então como isso fica diante do fato de que você é heterossexual?

- Isso só faz realmente alguma diferença quando eles me perguntam se eu sou gay ou não. Se eles não me perguntam é mais uma questão de manter a pose.

Paul descreve uma situação na qual as diferenças de classe não estão simplesmente sobrepostas às de raça. Além disso, a orientação sexual não parece ser uma fronteira determinante das interações e do cultivo de relações de amizade: pelo contrário, o entrevistado fala de um grupo de amigos, entre garçons e clientes, homossexuais e heterossexuais, que ultrapassa as interações no ambiente de trabalho. Entretanto, como mencionou um dos gerentes, "ser gay ou não" não é simplesmente uma questão de se "manter a pose". Alguns jovens rapazes (especialmente os blacks oriundos de townships) se seduzem por esse estilo de vida, se engajando frequentemente em relações afetivo-sexuais com homens que fazem parte da clientela. Um dos gerentes chamou atenção para a sedução que esse ambiente exerce sobre os jovens que se apresentam como heterossexuais quando contratados: alguns aos poucos vão se engajando em relações com homens 
gays, "fascinados" pela aceitação e pela busca por novas experiências de vida.

Além dessa cena homossexual predominantemente masculina, as etnografias na região da "Pink Strip" descrevem alguns espaços voltados ao público homossexual feminino, como a festa Lush. A proposta da festa é, na "cena dos clubs predominantemente direcionados a um público masculino gay"11, oferecer um ambiente voltado às mulheres lésbicas. Alinhando-se com tendências observadas em outros estabelecimentos da região, as observações de campo apontaram para a predominância de um público white.

Um ponto interessante sobre a organização dessa festa, que pretende fazer uma oposição a um padrão masculino identificado na "Gay Village" da Cidade do Cabo, é que a entrada de homens - quase proibida - passou a ser permitida para gays acompanhados de amigas lésbicas. A abertura da festa aos amigos gays das frequentadoras é apontada no seu próprio site online.

Além do público massivamente feminino da Lush, os pesquisadores identificaram alguns outros espaços na região destacados pela freqüentação predominante majoritária de coloureds ou outras identidades étnico-raciais.

O mapeamento dos bairros etnografados na Cidade do Cabo, mostrando os públicos que acessam as regiões descritas $e$ suas possibilidades de trânsito e participação nos diferentes eventos dessa cena, oferece um substrato que permite acompanhar as narrativas que seguem, por serem espaços nos quais suas performances corporais e identitárias são negociadas, suas experiências de pertencimento ou discriminação são vividas $e$ seus laços afetivos e eróticos são constituídos. Nesses locais foram identificadas tensões que articulam raça, língua, classe, gênero $e$ sexualidade na disputa por acessos e espaços de sociabilidade. ${ }^{12}$

${ }^{11}$ www.lushcapetown.co.za [acesso: novembro de 2009].

${ }^{12}$ A presença e a experiência do quadro diversificado de pesquisadores, inclusive por sua eventual familiaridade com esses locais, foi um elemento chave para o levantamento do material. 
Retóricas ambivalentes

\section{Interações, ressentimentos e negociações}

Atualmente, a combinação entre língua e cor/raça se apresenta como um profundo indicativo de classe, que vem diferenciando blacks de camadas baixas e de camadas altas. Nas regiões anteriormente citadas, a língua predominante é o inglês, embora alguns transitem entre o inglês e o africânder; notam-se alguns grupos falando xhosa entre si, por exemplo. Falar inglês significa, grosso modo, ser competente no mundo dos whites. No dia a dia, é importante controlar esta língua com um mínimo de habilidade, visto que é a língua predominante tanto das ações $e$ da burocracia governamentais, quanto do mundo dos negócios. Mas algo mais pode ser dito a esse respeito.

Poucos estão aptos a circular com competência pelas diversas esferas sociais diferentemente associadas à raça. Além disso, os custos são distintos. Um white que não fala xhosa tem mais chances de obter emprego e posições do que um african ou black que não fala ou que articula mal o inglês. Se esse é um importante sinal diferenciador de status, ele também indica a gama mais ou menos restrita de relações na qual o indivíduo poderá se engajar. De modo bem diverso do Brasil, na África do Sul, aprender inglês significa, de modo muito profundo, adquirir competência em outra cultura. ${ }^{13}$ Os conflitos presentes nesse processo não se restringem apenas à população black, visto que muitos africâneres, especialmente os mais idosos e moradores de regiões rurais, não falam inglês fluentemente. Frequentemente usado como sinônimo de raça ou cultura, o domínio de uma ou mais línguas é igualmente um indicativo de formas culturais de interação e informa tanto a construção de si quanto a rede de sociabilidade dos indivíduos.

Keneth, rapaz coloured, heterossexual, de 24 anos, expõe a forma como a língua cria barreiras em termos de interação com diferentes grupos ou pessoas:

${ }^{13}$ Ver sobre esse tema na África Austral, Fry (2003). 
Laura Moutinho et alii

(...) há uma barreira linguística, então acho difícil me comunicar, por exemplo, com falantes do africânder, porque eu não falo a língua tão bem. Eu tive aula de xhosa no high school, então falo um pouco, acho até que conseguiria manter uma conversa com alguma fluência.

Além de ser um importante leit-motiv para a construção de si, a língua informa o lugar social dos indivíduos, bem como as chances de engajamento em certas relações sociais com pessoas de outros grupos.

Não se pode esquecer que a África do Sul possui atualmente 11 línguas oficiais, mas o que parece estar em disputa é qual delas seria a língua nacional. Trata-se de uma verdadeira geografia imaginada, marcada pela controvérsia e pelos "duplos demoníacos" (Bhabha, 2005) que assombram a nação civilização/primitividade, exclusão/desigualdade, sentimentos de injustiça, experiências de desrespeito, dor e revanche. A obrigatoriedade do africânder nas escolas foi motivo de revoltas e controvérsias, como a que ocorreu em Soweto, Joanesburgo, em 1976. Na ocasião, centenas de estudantes saíram às ruas para protestar exatamente contra a obrigatoriedade do ensino do africânder. Esse debate, embora menos visível nas reflexões sobre a África do Sul pós-apartheid, mostra-se profundamente revelador de uma série de tensões e desafios.

Thoni, rapaz, black, de 22 anos, heterossexual, que na época da entrevista vivia em Lower Crossroads e crescera em um township conhecido como Newcrossroards, expressa esse incômodo:

Eu lembro que na escola primária nos ensinavam africânder... Mas eu realmente não gosto. Quando eu ainda trabalhava para Molo Songololo ${ }^{14}$, a gente ia acampar com crianças que falavam africânder. Eu sentia como se eu não

\footnotetext{
${ }^{14} \mathrm{http}: / /$ www.molosongololo.com/home/
} 
Retóricas ambivalentes

gostasse delas porque eu não gostava da língua que falavam. Isso não é uma boa coisa, claro. $\mathrm{O}$ africânder é como qualquer outra língua, mas eu não sinto vontade de usá-la. Se uma pessoa viesse falar africânder comigo eu ia dizer pra ela ou ele que não entendo. (...) Meus amigos têm me dito que eu devia ao menos aprender, mas eu continuo relutante. Minha relutância tem a ver com a história, eu acho. Nós éramos forçados a falar africânder, mas agora vivemos em um país democrático $e$ não há mais obrigatoriedade.

Língua símbolo do apartheid e da opressão, o africânder e outros símbolos que caracterizam os africâneres estão em disputa. Frequentemente, é possível ouvir que o African National Congress (ANC) desencoraja o uso dessa língua na TV - não há mais um canal público apenas em africânder. Diariamente são veiculados programas nesta, mas também em outras línguas, como o inglês e as chamadas "black languages" -, em documentos oficiais e em nomes de ruas e praças. Atualmente, a Stellenbosh University próxima à Cidade do Cabo (Western Cape), incrustada no coração de uma belíssima região vinícola (Winelands), e uma das mais importantes universidades sul-africanas, onde no período do apartheid não era permitido o ingresso de alunos não-whites -, vem sendo pressionada a incorporar outras línguas além do tradicional africânder. Um forte e poderoso grupo africâner continua mantendo a universidade com sua marca tradicional $e$ muitos argumentam que blacks, outros whites, coloureds e indians podem frequentar se quiserem outras universidades, sendo esta uma das poucas "sobrevivências" de uma cultura específica, disponível aos africâneres no pós-apartheid. Essas transformações e deslocamentos, em especial no que tange à memória urbanística (como as mudanças de nomes de ruas, praças e até mesmo cidades), são sentidas por muitos como uma forma de "genocídio" e uma tentativa de eliminação, portanto, da presença de um certo grupo étnico. Concomitantemente, alguns entrevistados argumentam que a contribuição $e$ interação de uma universidade 
de excelência como Stellenbosh com outros países, línguas e culturas seria muito maior (como acontece com a UCT), caso não atraísse apenas estudantes africâneres. Não se trata de um argumento persuasivo diante das marcas do passado e das transformações recentes. A manutenção desse espaço específico e de uma cultura igualmente específica mostra-se, no momento, uma questão central.

$\mathrm{O}$ aspecto que desejamos reter desse amplo debate refere-se ao lugar central que o reconhecimento oficial das línguas faladas na África do Sul adquiriu no âmbito do debate sobre direitos humanos, especialmente em relação às ideias de dignidade $e$ valorização da diversidade (veiculados histórica e cotidianamente através da expressão "rainbow nation") que são reivindicadas no pós-apartheid como a síntese de um novo país. A imagem da "rainbow nation" foi utilizada por Nelson Mandela pela primeira vez no discurso de posse em 10 de maio de $1994^{15}$, após as eleições que inauguraram a democracia, para se referir a uma nova era na qual a dignidade humana e a paz suplantariam a injustiça e a opressão raciais. A ideia de "arco-íris", cujas cores permitem ênfase na diversidade - deslocando-se da noção antes reinante de raça ou mesmo de cultura e de etnicidade -, evidencia a tentativa de implantar um projeto hegemônico de nação, no qual a raça seria abolida como marca de identificação e distinção sociais entre os diferentes grupos.

Nelson Mandela foi Presidente da África do Sul de 1994 a 1999, quando passou a administração do país a Thabo Mbeki. Personagem controverso, a gestão de Mbeki teve como marca a recuperação econômica, mas sob seu comando foi criada uma série de políticas de cunho raciais. Uma certa elite black ganhou destaque com o apoio nas ações afirmativas implementadas pelo governo (além de um espaço controverso na mídia) a partir desse período. Nesse sentido, o projeto hegemônico de nação

${ }^{15}$ http://www.info.gov.za/speeches/1994/990319514p1006.htm [acesso: agosto de 2010]. 
Retóricas ambivalentes

implementado por Mbeki rivaliza com aquele liderado por Mandela e pelo arcebispo Desmond Tutu dos primeiros anos da democracia. As diferenças nas estruturas de representação e poder evocam ainda outras faces da maneira como a competência linguística se articula à hierarquia racial.

Muzi - rapaz black, heterossexual, de 23 anos, fluente em inglês - partilhou uma situação em que se sentiu sob suspeição, justamente por contrariar certas expectativas relativas à raça (black) e ao domínio do inglês.

A raça não acabou, em termos de um certo tipo de discriminação, entende? Se você diz, por exemplo, que é de Khayalitsha ou Philippi ${ }^{16}$, não é como se não soubessem que é uma área predominantemente black ou que a escola que você frequentou era pública. É óbvio que você não tem como bancar uma escola particular. Então sempre tem formas de te localizar e de te posicionar. Por exemplo, eu tinha que ir a todos esses cursos [de inglês] para principiantes pelos primeiros seis meses para poder ter acesso, mesmo conseguindo acompanhar as coisas em um nível universitário. Teve uma vez que eu escrevi um ensaio que estava no nível do terceiro ano, e eu ainda no primeiro: acabei tendo que ir ao departamento de inglês (...). Lá eles me perguntaram que livros eu tinha lido e me pediram para entregar o arquivo do texto para verificar se não era plágio. E eu fiquei nessa reunião por uma hora com eles me perguntando por que eu tinha consultado aquele material $e$ coisas do tipo... Se fosse um rapaz white que tivesse feito a mesma coisa, eu sei que eles não teriam agido da mesma forma.

A narrativa de Muzi aponta para uma situação frequente, na qual a lógica racial, através do racismo que a constitui, informa de modo ora sutil, ora explícito, formas discriminação. Diferenciar e excluir pessoas com base na cor ou raça não é privilégio de um ou

${ }^{16}$ Townships nas imediações da Cidade do Cabo. 
outro grupo racial. A "realidade" do racismo tampouco é homogênea. Os whites sul-africanos (que são de grupos muito distintos) se configuraram historicamente, assim como os blacks (ou na linguagem colonial a genérica categoria "banto"), grupos raciais/culturais estreitamente diferenciados segundo a lógica essencialista do apartheid. Raça e racismo são diferentes entre si, uma vez compreendidos em seu cruzamento com outros marcadores sociais da diferença, como argumenta Avtah Brah (2006), e precisam ser analisados no interior do sistema de classificação e das relações de poder que lhe dão força e sentido.

Mandla - que como dito anteriormente se classifica como black, tem 21 anos, se apresenta como heterossexual, viveu na Suíça e nasceu em Zimbábue - narra sua experiência em Cape Town:

Blacks não me discriminam por causa da cor da minha pele, mas por minha etnicidade. No caso dos whites $e$ coloureds, eu sempre vi muito racismo indireto - até que cheguei à Cidade do Cabo, onde a preferência por determinados tipos de pessoa é um corte nítido. É como se você precisasse se comportar de uma forma específica, $e$ quando você não se comporta assim você choca... São esperadas certas coisas de você, se você for black, independentemente de você falar inglês ou não.

Nota-se, nesse contexto, um deslizamento entre diferentes termos: "etnicidade" emerge atuando de modo similar à lógica racial, no sentido de tornar inteligível a discriminação entre pessoas que poderiam ser de um mesmo grupo de cor, dependendo da forma como o sistema de classificação opera. Mandla aborda um problema delicado que já se delineava na época da realização da pesquisa, embora ainda não tivesse motivado os trágicos eventos ocorridos em $2008 .{ }^{17}$

${ }^{17}$ Em maio de 2008, houve uma onda de ataques a estrangeiros, iniciada em Joanesburgo. As agressões foram tomando força e se espalhando por outras 
Retóricas ambivalentes

Eu também já sofri xenofobia, pessoas com a mesma cor de pele que eu me discriminando... Acho que o principal fator tem a ver com a minha origem, com o lugar de onde venho $e$ a forma como fui criado. $\mathrm{O}$ fato de que eu falo inglês $-e$ com algum sotaque - me coloca em uma certa categoria... Eu recebi essa educação, e meus pais, bem, eu não diria que são ricos, mas certamente tínhamos melhores condições de vida que a maior parte das pessoas em meu país. O modo como eu reagi a isso foi muito negativo no começo, eu era muito apologético aos gifts [benefícios] que recebia. Mas agora eu estou num momento no qual eu os encaro como uma responsabilidade - há muitas expectativas envolvendo isso...

A xenofobia aparece no sentido de explicar a discriminação vivida entre aqueles que, como no excerto anterior, poderiam ser compreendidos como parte de um mesmo grupo racial. Trata-se de uma dinâmica perversa que guarda muito da mentalidade do apartheid. As hostilidades acentuadas na "old South Africa" fazem com que empregadores muitas vezes prefiram ter em seus quadros, profissionais de outros países. Muitos sentem que blacks de Moçambique, ou mesmo do Zimbábue, estabelecem uma relação menos tensa com os whites, por estarem mais distantes dessa experiência de opressão (e o consequente ressentimento) que os blacks sul-africanos viveram (e expressam).

Nesse caso, porém, há outro elemento importante: raça aparece metonimicamente associada à língua, tradição permeada por uma certa operação que a experiência diferenciada de classe impõe na cena social, que evoca a opressão e a pobreza. Apesar

regiões do país, tendo atingido inclusive a Cidade do Cabo. O ocorrido gerou uma série de debates na imprensa nacional e estrangeira, sendo levantadas interpretações de diversas naturezas: explicações que passaram por ódio racial, violência de gênero, disputa por emprego ou mesmo crimes de oportunidade. É possivel acompanhar uma importante parte do debate nacional no portal online do jornal Mail\&Guardian: http://www.mg.co.za/ 
de ter a mesma "cor da pele", Mandla é um "outro": fala inglês com sotaque reconhecível, traz experiências densas de outros países e vem de camadas altas. Nessa posição, ele desloca ( $e$ denúncia) os que não têm as mesmas habilidades (skills) $e$ competências exigidas nessas novas tramas de relações.

Como mostra Veronica a seguir, ser black e estrangeiro pode em outro contexto sinalizar respeito e em alguma medida aceitação:

- Se você encontrasse um pessoa de origem britânica que fosse black e você a achasse atraente...

- Bem, eu acho que nesse caso seria tudo bem, acho que meus pais só têm problemas com blacks sul-africanos. Eu sei que minha mãe tem muito respeito pelos blacks do Malawi.

O potencial de violência dessas intricadas redes de relações, permeadas pela chance de acesso a bens, status e emprego, emula o processo de empatia e reconciliação em curso, competindo portanto com os múltiplos significados (e ações) estimulados pela força da divisão racial e pelo racismo.

"Responsabilidade", uma noção agregada a "compromisso", aparece frequentemente no cotidiano. Se Mandla compreende suas habilidades derivadas de sua situação social privilegiada como "responsabilidade", em outros contextos $e$ situações o "compromisso" com a construção de uma nova África do Sul, bem como com o próprio continente africano e suas mazelas, repetidamente é evocado em conversas sobre os rumos políticos do país ou mesmo quando se comenta sobre o apartheid. Nesse contexto, "responsabilidade" e "compromisso" aparecem como uma maneira de retornar o processo de empatia com o "outro" desviado pelo racismo ou mesmo pela xenofobia. A linguagem estimulada pelo processo de reconciliação é, desse modo, retomada em outro eixo. Voltaremos a este ponto. Antes se faz necessário olhar para alguns conflitos e tensões que se tornam 
Retóricas ambivalentes

evidentes quando abordamos as diferenças de classe entre um mesmo grupo racial.

"Coconut" (preto por fora e branco por dentro) é uma expressão utilizada contra blacks em processo de ascensão, ou que evidenciem habilidades características do mundo white. Bsy nos narra a sua experiência:

Isso acontece o tempo todo, aqui na Cidade do Cabo e em Johanesburgo também... Mais de uma vez por mês. Não necessariamente nessas palavras [coconut], mas isso realmente dói. Por exemplo, tem essa menina no meu trabalho que me irrita. Em outros momentos ela é legal, mas tem esse jeito... Ela é black e hoje, por exemplo, eu estava com alguns colegas whites no meu intervalo de almoço - e há essa expectativa de que se eu vir um black eu certamente cumprimentaria, porque eu também sou black: se eu não falasse com esta pessoa eu estaria indicando que penso que sou melhor do que ela, ou que sou uma white... E não é o caso, tem vezes que eu simplesmente não estou com vontade de conversar com alguém...

Bsy evidencia ainda outras dificuldades vividas no sentido de estabelecer amizades ou mesmo paqueras com whites.

(...) tem esses momentos em que você está num grupo misto de pessoas e acham que você quer passar por white ou algo do tipo... Eu não sei por que as pessoas acham tão difícil entender como eu posso ter amigos whites. Eu faço amigos baseada no fato de termos interesses em comum, mas há blacks que não sabem quem eu sou e no que eu me interesso que não conseguem entender porque eu saio com algumas pessoas, ou porque gosto delas. No ano passado, aconteceu uma coisa que realmente me deu vontade de chorar. A gente foi ao mercado de pulgas de Milnerton, eu e umas quatro pessoas whites. Em um momento, eu estava caminhando entre dois dos rapazes e um senhor black, de 
tipo uns 50 anos, veio na minha direção, ficou me olhando com uma cara de repulsa e cuspiu no chão. Tipo, é comum eu ter essas experiências... quando eu saio com um grupo de whites, ou com um cara white com quem eu esteja ficando... outros blacks costumam ter muito o que dizer, não em inglês, mas em zulu ou xhosa. Para mim é a coisa mais dolorosa....

Nas duas experiências narradas, vemo-nos diante de situações distintas, mas interligadas. "Coconut" é uma categoria de acusação que alimenta rumores, impõe limites e provoca (melhor seria dizer visa conter) mudanças de comportamento. Como aponta Salo (2010), trata-se de uma categoria frequentemente dirigida a

mulheres jovens que adquirem bens materiais, tais como ousadas e provocativas roupas de moda e capital cultural como a habilidade de falar inglês, e/ou xhosa, e que transitam por espaços considerados pouco familiares e cosmopolitas da cidade, como o turístico Waterfront, ou ambientes mais caseiros, e mesmo assim pouco familiares, como discotecas e shebeens das áreas (subúrbios) xhosa ${ }^{18}$.

O que vemos, nesse sentido, é a tentativa de conter experiências e relações não marcadas pela raça ou pela cultura tradicional que, concomitantemente (embora não de modo exclusivo) denuncia tensões e rupturas entre gerações distintas. A pressão sofrida por Bsy ecoa a lógica segregacionista que se articula à manutenção de convenções acerca de expectativas baseadas em gênero e sexualidade do antigo regime. Evidencia,

18 "younger women [who] actively acquire material goods such as fashionble, sexily risque dress, and cultural capital such as the ability to speak English, and/ or isiXhosa and be seen to traverse the otherwise unfamiliar cosmopolitan spaces of the city such the touristy Waterfront or the more homely discotheques and shebeens in the surrounding though unfamiliar Xhosa -speaking suburbs". 
Retóricas ambivalentes

portanto, os diferenciais de gênero e sexualidade articulados à raça e expõe o marcador de classe como um mecanismo que em parte possibilita um terreno comum de trocas a despeito das diferenças de raça (e mesmo gênero, nesse caso), mas de outra parte ameaça a tradição (também racialmente engendered) $e$ comportamentos anteriormente acordados.

Cindi, 22 anos, lésbica e black, que cresceu em Phillipi e atualmente mora com a parceira em Khayelitsha (outro township), vivencia em sentido diverso o domínio de uma língua e suas chances no mercado dos afetos e prazeres:

Apesar de não ter problemas com outras raças eu não teria, por exemplo, uma parceira white nem um indian, porque detesto falar inglês o tempo inteiro. Eu adoro a minha língua [xhosa] e meus amigos sabem que eu tenho limites falando inglês.

Por um lado, as cenas narradas mostram a força de um estilo de vida (ou de classe) similar para que um certo repertório linguístico $e$ performativo possa ser operado positivamente; por outro, essa tendência rivaliza com outra e se atém a convenções comunicativas mais sintomatizantes (Crapanzano, 2001). Ao restringir suas opções tendo como base a língua, Cindi não se engaja em uma relação com mulheres de outra raça. Impossível nesse ponto não evocar Cronjé - um dos principais ideólogos do apartheid. Para Cronjé, o convívio entre raças distintas enfraqueceria os sentimentos e hierarquias raciais. Ao partilhar o cotidiano com outros grupos raciais, os whites (ele pensa aqui nos africâneres) acabariam por desenvolver um sentimento de igualdade - um "abastardamento" da diferença racial ("blunting process", como anteriormente mencionado) que suplantaria seu sentimento de pertencimento ao volk (Moutinho, 2004a; Ribeiro, 1995). Se em parte Cronjé estava correto - o convívio tem potencial para produzir empatia e um novo sentido de 
humanidade -; de outra parte, entretanto, vê-se, pela forma como o sistema de classificação racial foi rigidamente concebido (especialmente na metonímica relação entre língua, tradição $e$ etnicidade), que são inúmeras as dificuldades de se construir $e$ experenciar a alteridade. Tendência que, como visto, ganha novos contornos a partir do processo ascensional nas novas redes de sociabilidade e através do manejo da língua inglesa.

$\mathrm{O}$ relato de Cindi, que diversas vezes ao longo da entrevista afirmou seu orgulho em ser falante do xhosa, acresce a essas narrativas algumas dimensões ainda mais concretas. Suas ponderações reafirmam a rigidez do sistema de classificação racial sul-africano - tanto nos casos que descreveu, quanto por sua própria forma de conceber as relações -, e apontam para algumas consequências sociais, especialmente na definição de vetos $e$ acessos a alguns mercados. $\mathrm{O}$ foco de suas reflexões remete à maneira como é construída a preeminência da língua inglesa, a contrapelo do discurso da igualdade e diversidade linguística.

Whites ainda têm mais oportunidade que nós africans, por causa da língua. Por exemplo, no ano passado eu me inscrevi na UCT, mas não tive êxito porque o meu inglês não estava de acordo com os padrões. Minha primeira língua é xhosa, e eu amo meu xhosa (...). Eles não olharam para a performance acadêmica, mas para o inglês. Entende o que eu quero dizer? Whites têm mais vantagens por causa da língua e do dinheiro. Eles falam inglês em casa, têm internet nos seus quartos e recursos. (...) Eles falam inglês dia e noite, e quando vão a uma entrevista, isso não é um problema. (...) Essas pessoas têm dinheiro, eles podem ir a hospitais particulares a qualquer hora. Podem estudar no exterior, se quiserem. (...) Eles têm melhores oportunidades de emprego por causa da língua e do acesso a informação. São expostos a outras coisas na infância.

O discurso de Cindi é marcado por forte - e rígida classificação racial. "Whites são", "whites têm", em oposição a 
"nós". Cindi também não visualiza, no momento de expressar suas desvantagens, que há, como já mencionado, whites em "hospitais públicos" ou mesmo "abrigos". Sua contundente e sofrida experiência de interdição ao acesso a diversas esferas da vida social - academia, internet, hospital, empregos - é explicada por uma diferença racial e de domínio da língua inglesa, que ela mesma aponta como historicamente construída. Nesse contexto a fluência em xhosa não funciona como senha de acesso. Assim, a memória de um Estado que diferencia seus cidadãos em categorias de raça articula-se a outras experiências vividas $e$ apresenta a diferença racial como encopassando as diferenças da classe, escolaridade e oportunidades no mercado de trabalho.

Por outro lado, esse discurso não aparece em uníssono no leque de entrevistas realizadas na Cidade do Cabo. Diferentemente de Cindi, Clide - rapaz black, gay, de 19 anostem uma trajetória muito mais marcada pela sensação de conforto e sucesso no ambiente escolar, universitário e de trabalho embora seja igualmente morador de um township. Ele relata que o inglês, língua que domina bem, deveria operar como uma forma de patamar de igualdade entre falantes:

Pessoas de outros grupos linguísticos... eu não tenho problemas com eles, contanto que falem uma língua que eu entenda. Se você quer se comunicar, fale comigo em inglês, e não venha falar africânder. Se você fala uma língua que eu não entendo, isso me diz que você está me discriminando.

Nas falas dos entrevistados, é recorrente uma ideia específica de mistura racial marcada por posicionamentos ambivalentes. Alguns argumentam em favor da não pregnância da clivagem por raça no campo das escolhas afetivo-sexuais. Entretanto, a identificação racial dos parceiros é acionada quando falam de suas trajetórias na esfera dos afetos e prazeres. Ainda que algumas pessoas identifiquem os espaços de sociabilidade que 
frequentam como não-segregacionistas em função de um público multi-racial, dificilmente os grupos são compostos por pessoas de diferentes raças: muitas vezes, estão apenas ocupando o mesmo espaço. Quando se identificam casais inter-raciais, eles são aproximados dos casais do mesmo sexo, sob o signo da "diversidade" - nesse eixo ambos são um sinal positivo dos novos tempos. Em outro eixo, entretanto, mesmo as pessoas que dizem que não gostam de "put people in boxes", dificilmente operam num registro que desconsidere, de fato, a diferença racial (o racismo e mesmo a homofobia) no sistema classificatório com o qual elas operam e que informa suas experiências cotidianas.

Mas há reações e reposicionamentos de sentidos $e$ significados. John - rapaz coloured, heterossexual, de 21 anos expressa suas ideias acerca de raça e das experiências de racismo:

Eu acho raça uma coisa realmente sem sentido/ruim [such a fucked up thing]. Como nós enquanto humanos podemos pensar que somos melhores que quaisquer outros só por que temos cores diferentes de pele? Digo, existe racismo mesmo no interior da comunidade black. Quanto mais claro melhor. E tem também a questão de onde você vem. Eu já vi blacks sul-africanos discriminando outros blacks que não eram daqui, e na maior parte das vezes é porque eles não falam a mesma língua. O mundo tá tão sem sentido. As pessoas precisavam aprender a respeitar umas às outras.

O destempero de John expressa não somente revolta, mas, sobretudo, o cansaço de muitos sul-africanos diante da inevitabilidade do racismo. Ao refletir sobre Auschwitz, Richard Rorty (2007:312) argumenta:

aquilo que figura como um ser humano honrado é relativo às circunstâncias históricas, é uma questão de consenso transitório quanto às atitudes tidas como normais $e$ às práticas tidas como justas ou injustas. 
Retóricas ambivalentes

Desse modo, concomitantemente com as experiências de exclusão, registra-se a existência de um campo recoberto pela dúvida acerca do vocabulário (Rorty, 2007) que as famílias e grupos de origem articulam para construir e narrar seu dia a dia. Se mover entre várias línguas, por exemplo, é um recurso para lidar com antigas formas de se relacionar.

O campo de possibilidades aberto para esses jovens - as fronteiras em negociação bem como o caleidoscópio de (re)posicionamentos sociais e (inter)subjetivos - está imerso em profunda ansiedade: jovens africânderes confrontados com um passado (dos pais e do país) do qual não podem nem mudar nem se orgulhar, um presente que retém privilégios, mas igualmente perdas. Perdas e privilégios aliás que estão igualmente presentes nas narrativas de blacks e coloureds em processo de ascensão: o passado está contra e a seu favor, a legitimidade do sofrimento está do lado deles, mas há custos e benefícios nesse processo. Há uma "prisão narrativa" (Das, 1999) contra a qual eles tentam se libertar, mas que adentra as cenas sociais cotidianas de diferentes formas, articulações e através de inúmeras justaposições, que podem aparecer na articulação entre gênero, raça e tradição - o que se espera do comportamento de uma mulher na cultura local ou talvez nas dificuldades de se assumir como lésbica numa outra tradição que recusa a associação entre cultura negra homossexualidade. Sabe-se que é preciso usar preservativo numa relação sexual, mas como comprá-lo de um senhor ou senhora africâner ou zulu a quem se deve respeito, que opera com específicos códigos de honra em relação às mulheres $e$ a quem, além de tudo, se é obrigado a chamar de tio ou tia mesmo que eles não sejam parentes? 
Laura Moutinho et alii

\section{Retóricas ambivalentes}

A ansiedade desses jovens frente ao futuro que os espera traz igualmente dúvidas sobre os repertórios que eles adquiriram acerca das expectativas e performances de gênero, raça, sexualidade, herdados de suas famílias e culturas. $\mathrm{O}$ desenvolvimento de um novo vocabulário e formas de pensar é marcado por ambiguidades e rancores, mas também por uma forma de compreensão somente visível depois que eles passam por uma espécie de conversão. Foi possível notar ao longo da pesquisa que essa conversão diz respeito à possibilidade de se operar de forma menos icônica e literal. Esse é o momento, às vezes fugidio, em que os indivíduos conseguem pensar e se expressar não através de essencializados marcadores da diferença, mas considerando-os como parte da estrutura e da desigualdade sociais mais ampla. Encontros inusitados acontecem nesse momento, como o de um rapaz africânder que disse preferir ir a um bar gay de predominância black (ele se apresenta como heterossexual) porque "sente" que eles prescindem de certos rituais de arrogância e enfrentamento presentes nas cenas masculinas e heterossexuais entre blacks e whites. Forja-se nesse momento um outro sentido de humanidade e uma nova relação social ganha espaço e curso.

Os fragmentos e narrativas que seguimos nesta análise evidenciam como um conjunto de marcadores sociais da diferença é articulado num contexto que mobiliza, concomitantemente, reconciliação e violência: um texto, que como argumenta Veena Das (1999:31) "é constantemente revisado, revisto, acrescido de comentários (...) [em contínuo] processo de produção”. Cotidianamente, uma verdadeira batalha de gestos, vocabulários, sentidos e (re)posicionamentos é vivida. Os ressentimentos e a exclusão (que não são em absoluto categorias auto-evidentes) partilhados por alguns criam novas comunidades de sentidos ${ }^{19} e$

${ }^{19}$ Ver, por exemplo, a trajetória de Mpho, no artigo de Bagnol et alii nesta coletânea. 
Retóricas ambivalentes

adesões, mas igualmente reposicionam indivíduos em novas (e antigas) situações de assimetria e hierarquia, a partir dos sentidos atribuídos a marcadores sociais como raça, língua, gênero $e$ orientação sexual. ${ }^{20}$ Mais do que especificar ou construir sujeitos em certos contextos (mais ou menos desejáveis nos mercados dos afetos e prazeres, das amizades, do trabalho) ou revelar as assimetrias de poder que se constroem a partir da complexa e sutil operação dessas clivagens, vê-se na tessitura do cotidiano disputas acerca da construção do "nós" e do "outro" - tanto internamente como pelas tensas (e dolorosas) experiências partilhadas por Bsy, quanto na radicalidade que desliza para cenários mais criminalizáveis como a violência xenófoba.

\section{Referências bibliográficas}

ÁFRICA DO SUL. Constitution of the Republic of South Africa, 1996. [http://www.info.gov.za/documents/constitution/1996/96preamble.htm ].

AgUiÃO, Silvia. "Aqui nem todo mundo é igual". Cor, mestiçagem e homossexualidades numa favela do Rio de Janeiro. Dissertação de Mestrado em Saúde Coletiva, Área de Gênero, Sexualidade e Saúde. Rio de Janeiro, IMS/UERJ, 2007.

BHABHA, Homi. O Local da Cultura. Belo Horizonte, Editora UFMG, 2005.

BRAH, Avtar. Diferença, diversidade, diferenciação. Cadernos Pagu (26), Núcleo de Estudos de Gênero - Pagu/Unicamp, 2006, pp.329-376 [http://www.scielo.br].

CRAPANZANO, Vincent. Estilos de interpretação e a retórica de categorias sociais. In: MAGGIE, Yvonne e RESENDE, Cláudia. (orgs.) Raça como Retórica: a construção social da diferença. Rio de Janeiro, Civilização Brasileira, 2001.

${ }^{20}$ Sobre as manobras possíveis de negociação de certos marcadores sociais da diferença (e da desigualdade), bem como o espaço de agência dos indivíduos no Brasil, ver Moutinho (2006), Aguião (2007) e Simões et alii (nesta coletânea). 
. Waiting: the whites of South Africa. New York, Random House, 1985.

DAS, Veena. Fronteiras, violência e o trabalho do tempo: alguns temas wittgensteinianos. Revista Brasileira de Ciências Sociais, vol.14, $\mathrm{n}^{\circ}$ 40, 1999, pp.31-42.

Douglas, Mary. Pureza e perigo. São Paulo, Perspectiva, 1966.

FERGUSON, James e GUPTA, Akhil. Mais além da "cultura": espaço, identidade e política da diferença. In: ARANTES, A. A. (org.) Espaço da diferença. Campinas-SP, Editora da UNICAMP, 2000 [1992], pp.31-49.

FONSECA, Claudia. Concepções de família e práticas de intervenção: uma contribuição antropológica. Saúde e Sociedade, vol. 14, n 2 , 2005, pp.50-59 [http://www.scielo.br].

FrASER, Nancy. Reconhecimento sem ética?. In: Lua Nova (70), São Paulo, 2007, pp. 101-138. [ http://www.scielo.br].

FRY, Peter. Culturas da diferença: sequelas das políticas coloniais portuguesas e britânicas na África Austral. Afro-Asia, 29/30, 2003 pp. 271-316. [http://www.scielo.br].

MOUTINHO, Laura. Ressentimento, dor e solidariedade: narrativas sobre raça, gênero e nação na nova África do Sul. XXXIII Encontro Anual da ANPOCS, Caxambu-MG, 2009.

Negociando com a adversidade: reflexões sobre "raça", (homos)sexualidade e desigualdade social no Rio de Janeiro. Estudos Feministas, vol. 14, $\mathrm{n}^{\circ}$ 1, 2006, pp.103-116 [http://www.scielo.br].

- Razão, "cor" e desejo: uma análise comparativa sobre relacionamentos afetivo-sexuais "inter-raciais" no Brasil e África do Sul. São Paulo, Editora da UNESP, 2004a.

. "Raça", sexualidade e gênero na construção da identidade nacional: uma comparação entre Brasil e África do Sul. Cadernos Pagu (23), Campinas-SP, Núcleo de Estudos de Gênero Pagu/Unicamp, 2004b, pp.55-88 [http://www.scielo.br]. 
Retóricas ambivalentes

RIBEIRO, Fernando Rosa. Apartheid e democracia racial: South Africa and Brazil in contrast. Tese de doutorado, Universidade de Utrecht, 1995.

RORTY, Richard. Contigência, Ironia e Solidariedade. São Paulo, Martins Fontes, 2002.

SALO, Elaine. Coconuts do not live in Townships: Cosmopolitanism and its Failures in the Urban Peripheries of Cape Town. In: Feminist Africa. Vol. 13, AGI/UCT, 2010 pp. 11-21.

Respectable Mothers, Tough Men and Good Daughters: Producing Persons in Manenberg Township - South Africa. Thesis $(\mathrm{PhD})$ submitted to Emory University - Department of Anthropology, 2004. 